forms should continue to be the responsibility of the two broadcasting authorities and provided as part of comprehensive services. It recommends that the broadcasting authorities should consult with professional bodies as to the practicability of broadcasting courses of adult education of a vocational nature and that they should try every possibility of improving arrangements for consultation and liaison with the recognized adult educational organizations.

The technical considerations discussed in Chapter 16 are reasonably summarized in the Committee's recommendations on this section. The B.B.C. has so far built twenty-one very-high-frequency sound stations, which serve more than 97 per cent of the population, and, within the frequencies allocated, it is impossible to provide for more high-powered stations, although low-powered relay stations or satellites could be provided, and coverage extended or improved in areas where it is now unsatisfactory. There were no representations that either the B.B.C. or the Independent Television Authority has not executed its plans for expansion as fast as was reasonably possible. The Committee concludes that short-term difficulties and disadvantages of changeover do not outweigh the long-term advantages to be derived from the adoption of the 625-line definition standard recommended by the Television Advisory Committee in its report of May 1960. Accordingly, it recommends that a change in the definition standard in the United Kingdom from 405 to 625 lines be authorized forthwith. A compatible service of colour television should be introduced on this standard, and the further extension of television services should be by broadcast transmission in the V.H.F. Bands IV and $\mathrm{V}$. This decision will involve building very-highfrequency transmitting stations, and the Committee recommends that these transmitting stations of the B.B.C. and the Independent Television Authority should be co-sited and that the Postmaster-General should be given appropriate powers of direction. In allotting the uncommitted frequencies in Band III, it is recommended that first priority should be given to separating the B.B.C.'s service to Wales from that to the English regions, and the second to improving the reception of the two existing programmes and completing their coverage.

\title{
CENTRAL ELECTRICITY GENERATING BOARD NEW RESEARCH LABORATORIES
}

$\mathrm{A}$ CEREMONY to mark the official opening of the Research Laboratories of the Central Electricity Generating Board at Leatherhead was held on May 10. After an introduction by Sir Christopher Hinton, the laboratories were declared open by the Right Hon. Richard Wood, Minister of Power. Dr. J. S. Forrest, director of the Laboratories, replied. Reference was made by the speakers to the fact that research on a national basis by an electricity authority was initiated in Great Britain in 1930 by the Central Electricity Board. At that time the National Grid was under construction and the need for the experimental investigation of certain problems in high-voltage transmission had been recognized. Small laboratories were established at Croydon and Waddon, and it was of particular interest to note, in connexion with the opening of the new laboratories, that the first member of research staff to be appointed was Dr. J. S. Forrest, the present director.

The Central Electricity Board first set up a laboratory at Leatherhead on a temporary basis in 1940 following damage by enemy air attack at the Waddon laboratories. This site, adjacent to the railway line, at Kingston Road, was afterwards developed, and between 1950 and 1955 had erected on it a number of permanent buildings, including a small high-voltage laboratory. During the same period facilities had been secured on nearby land at Cleeve Road for the erection of a $400-\mathrm{kV}$ experimental high-voltage transmission line. This land adjoined the research laboratories of the Electrical Research Association. It is on a 20-acre site adjacent to the experimental high-voltage line that the new laboratories have been erected (Fig. 1). These comprise a main building with a floor area of about 100,000 square feet, a separate high-voltage laboratory of 35,000 sq. ft., together with a radiographic laboratory, a staff restaurant and recreation building. The buildings at Kingston Road now house the materials division of the laboratories.
The total staff of the laboratories numbers about 750 , of whom roughly one-third are professional engineers or scientists.

The Central Electricity Research Laboratories are organized on the basis of five research divisions described as: High Voltage, Physics, Engineering, Chemistry and Biology, and Materials ; and in addition there are the supporting technical and secretarial services.

The lay-out of the main block of buildings has been arranged architecturally in rather an interesting way. The pond for cooling water and fire fighting has been made a central feature in front of the build. ing and over part, on a sort of isthmus on stilts. stands the lecture theatre. The main block, three storeys high, is backed by two wings each two storeys high, separated by an area at present used as a car park. Behind the west wing is situated the canteen, and in fairly near proximity are a temporary workshop and stores. Some 150 yards away to the north is the high-voltage laboratory and not far from it a small X-ray laboratory.

The ground floor of the main block houses the library, one of the drawing offices, the photography section, together with the typing room, duplicating facilities and administrative offices. The first and second floors are occupied by chemistry, physics. electronics and biology laboratories, the accommodation comprising for the most part rooms ranging in size from 200 to 1,250 sq. ft.

The design of the two wings was influenced by experience gained in earlier laboratories. This had demonstrated the necessity of providing fairly large areas of floor space on ground-level on which heavy experimental plant could be erected. Large-scale 'test rigs' require access to the major engineering services, suitable arrangements of foundations. head room, crane facilities and access and transport facilities. Indeed, the provisions required are similar to those of the 'test bed' of a manufacturer of machinery or electrical plant. One such area is provided 


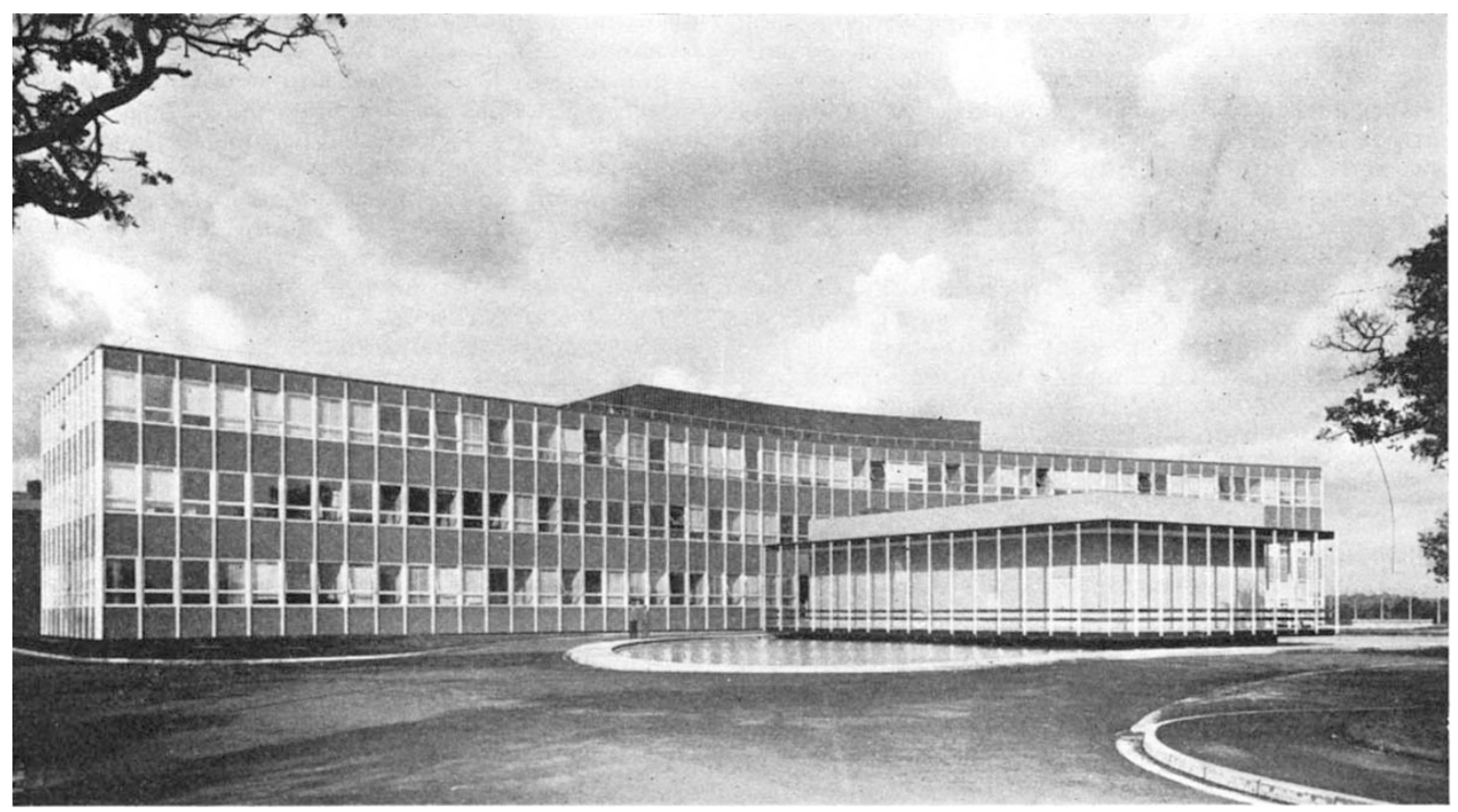

Fig. 1

in each of the wings, the dimensions being $200 \mathrm{ft}$. by $60 \mathrm{ft}$. These areas are flanked by laboratories and small rooms on two floors.

The high-voltage building has a total working area of $35,000 \mathrm{sq}$. ft., the main bay of the laboratory having an area of $12,000 \mathrm{sq} . \mathrm{ft}$. and a height of $70 \mathrm{ft}$. The planning of these laboratories was completed in 1958 , and parts of the new buildings were completed and occupied by January 1961. By the end of the year all the buildings were complete and in full operation.

Work in progress was demonstrated in all five Divisions of the laboratories. Terminating at the High-Voltage Laboratory is a new experimental line, a double-circuit single-phase line which will be used to study line corona and insulator losses and radio noise from multiple bundle conductors at system voltages up to the equivalent of $840 \mathrm{kV}$ three phase. The equipment of the High. Voltage Laboratory itself will provide power frequency voltages up to $1.2 \mathrm{MV}$ r.m.s. and impulse voltages up to $4 \mathrm{MV}$ peak. Studies of the breakdown and deterioration of the dielectrics used in transformers, switchgear and cables form an important part of the work of this division. In addition, the division investigates the current-carrying capacity of conductors for overhead lines and substations, and for this purpose equipment is available for producing currents up to $100 \mathrm{k}$.amp. A particu. larly interesting group of investigations in the same division concerns magnetohydrodynamic generation. These comprise a $2 \mathrm{MW}$ oil-burning jet, a shock-tube experiment and a plasma-jet experiment together with a mercury closed cycle equipment.

In the Physies Division work on solid-state physies deals with the fundamental electric and electronic properties of new materials which are likely to have application in the supply industry, for example, semi-conducting oxides, liquid semi-conductors and metals in the super-conducting state. Associated with this work is apparatus for the growth and preparation of single crystals, zone melting apparatus, and there is an automatic recompression system for the recovery of helium gas evolved during experiments using liquid helium. Localized electron states in solids are being studied by means of an electron spin resonance spectrometer.

The mathematical work of the Division is naturally much concerned with the expression of physical problems in mathematical forms suitable for analytical or numerical solution. The resources of the Board's Computing Centre situated at Gordon House in London are utilized for numerical computation. Typical of the physical problems which are encountered are: the diffusion of gases in the atmosphere, the scattering of electromagnetic waves by plasma and the oscillation of a freely suspended catenary in the atmosphere. There is, in addition, a range of important problems concerned with the automatic control of transmission line networks and of associated generating equipment.

In the laboratories as a whole there is a central instrument service which is provided by the Physics Division. For the most part, existing commercial equipment is utilized but a substantial effort is devoted to the development of new instruments and systems. The non-destructive examination of materials and of components is another of the Physics Division's responsibilities and the equipment provided for this purpose includes apparatus for the generation and detection of ultra-sonic waves and X-ray equipment giving complete coverage within the range $10-400 \mathrm{kV}$.

Mechanical and civil engineering, including specialized sections dealing with fluid dynamics and heat transfer, constitute the main fields of activity of the Engineering Division. A long-bed tensile testing machine provides facilities for the testing of transmission line conductors in lengths up to $77 \mathrm{ft}$. and heating current up to 3,000 amp can be circulated through the specimen. An equipment has been built for the tri-axial testing of concrete at elevated temperatures. This research relates to pre-stressed concrete pressure vessels. Strain-gauge measurements naturally play an important part, and consider. able effort is devoted to the study of special techniques associated with the various uses of strain gauges. One such investigation concerns the practic. 
ability of using resistance strain-gauges for measuring the vibrations of turbine blades under service conditions. There is a vibration testing laboratory in which, at present, static vibration tests are being carried out on models of steam turbine-blading in order to determine their resonant modes.

Photo-elastic analysis is applied to the investigation of stresses in pressure vessels, steam headers and fuel element cans.

Measurements of particle size and other studies related to powders and dusts are carried out on materials such as fly ash and pulverized coal.

The work of the Division of Chemistry and Biology ranges from a group of researches on fuel cells to studies in marine and fresh-water ecology. The effects of power station operation on the ecology of marine and fresh-water organisms is a matter of increasing importance.

The analysis of flue gases, an important and traditional chemical measurement in thermal power stations, is now carried out by gas chromatography. Research is in progress on apparatus for effecting remote control of combustion by means of a computer handling automatically data provided by a gas chromatograph. The efficiency of different absorbent materials in extracting sulphur dioxide from flue gases is a related topic.

Internal corrosion in boilers is studied with the help of an experimental boiler, and work is also in progress on the fouling and corrosive effects of combustion products on the fire-side of boilers.

Although the scope of the Materials Division is in no way restricted to metals, the main effort is at present directed to metallurgical research, especially to performance at elevated temperatures in particular applications. Mechanical testing, involving hightemperature tensile, creep and fatigue tests, thus plays an important part. The effects of wolding, stress relieving and other fabricating procedures are also studied. Much attention is devoted to austenitic steels used at temperatures above $550^{\circ} \mathrm{C}$. Materials which may be of importance in high-temperature equipment for the direct generation of electricity are also the subject of investigation. Magnetohydrodynamic generation, for example, will require insulating duct materials and conducting electrode material capable of withstanding temperatures in excess of $2,000^{\circ} \mathrm{C}$ for long periods. Silicon carbide has potential importance in high-temperature rectification, and apparatus has been designed to grow single crystals of this material epitaxially.

The supporting technical services of the Laboratories were illustrated by an interesting series of exhibits in the central workshops and drawing offices. Machine and assembly work, profile cutting, welding, chassis wiring, armature rewinding and cable jointing were in progress.

Design and workshop drawings for mechanical and electrical equipment were shown in the drawing offices together with illustrative work.

In the photographic section examples included high-speed still and ciné photography, photomicrography and colour photography.

The opening of these new Laboratories serves further to demonstrate the will of the supply industry to maintain and to improve its position by its ability to absorb and to apply new scientific knowledge and. in addition, to make its own contribution to fundamental advances. It is important to realize that the Central Electricity Research Laboratories constitute only one of a group of major research projects operated by the Central Electricity Generating Board. The Berkley Nuclear Laboratories are exclusively concerned with the special problems of nuclear power stations. A further research station, designed to undertake large-scale experiments in the field of generation and transmission, is being established at Marchwood on Southampton Water. In addition, each of the five regions of the Generating Board has a regional research organization devoted primarily to the solution of problems in the operation of power stations and of the Grid System in its own area. All these organizations, with a research staff totalling some 1,300 , contribute to the research effort devoted to improving electricity supply.

J. GREIG

\section{ROTHAMSTED EXPERIMENTAL STATION}

\section{REPORT FOR 1961}

$\mathrm{T}$ HE diversity of modern agricultural research is well exemplified in the annual report of the Rothamsted Experimental Station for 1961*. It covers the activities of the twelve research departments at Rothamsted, the farms there and at Woburn, the experimental stations at Woburn and at Dunholme and the work of the Soil Survey of England and Wales. Of the 296 pages in the report, more than 200 describe investigations actually in progress or just completed and a short review can scarcely do justice to the year's work of this, Britain's premier, agricultural research station.

Of topical interest and importance are the results of a ley-arable rotation experiment designed to assess the effect of the ley on soil fertility and the performance of subsequent crops. Since Stapledon so forcefully and successfully advocated the use of the ley before

* Lawes Agricultural Trust. Rothamsted Experimental Station, Harpenden. Report for 1961. Pp. 296. (Harpenden, Herts: Rotham- and during the Second World War, it has been widely assumed that the benefits were automatic. Farm practice has often seemed to confirm this, but in fact critical experimental data, either for or against, are singularly few. For several years the Rothamsted experiment has becn running in two parts, one on a field ploughed from old pasture and the other on land long under an arable rotation. The test crops were wheat, potatoes and barley, and the results, apart from a few interesting but minor variations, show that no definite improvement in yield has followed the ley that cannot, just as easily, be secured by the use of fertilizer in a purely arable rotation. Ley-arable rotations do not lend themselves very readily to really critical experimental control, and the danger of generalization from one set of experiments is obvious, but the work is valuable just because of this. We may well have overstated the case of the ley as a universal panacea and a well-based re-appraisal will certainly do no harm. 